Article

\title{
New Insights into the Roles of Osmanthus Fragrans Heat-Shock Transcription Factors in Cold and Other Stress Responses
}

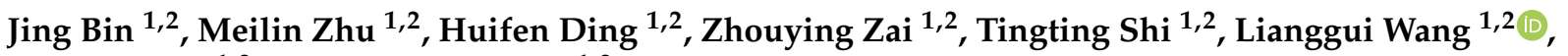 \\ Xiulian Yang ${ }^{1,2}$ and Yuanzheng Yue ${ }^{1,2, *}$ \\ 1 Key Laboratory of Landscape Architecture, Jiangsu Province, College of Landscape Architecture, \\ Nanjing Forestry University, Nanjing 210037, China; LLSutopia@163.com (J.B.); \\ z18720278614@163.com (M.Z.); 15797954948@163.com (H.D.); azdzwy36@163.com (Z.Z.); \\ tingtingshi@njfu.edu.cn (T.S.); wlg@njfu.com.cn (L.W.); xly@njfu.edu.cn (X.Y.) \\ 2 Co-Innovation Center for Sustainable Forestry in Southern China, Nanjing Forestry University, \\ Nanjing 210037, China \\ * Correspondence: yueyuanzheng@nifu.edu.cn; Tel.: +86-27-85428770
}

\section{check for} updates

Citation: Bin, J.; Zhu, M.; Ding, H.; Zai, Z.; Shi, T.; Wang, L.; Yang, X.; Yue, Y. New Insights into the Roles of Osmanthus Fragrans Heat-Shock Transcription Factors in Cold and Other Stress Responses. Horticulturae 2022, 8, 80. https://doi.org/10.3390/ horticulturae 8010080

Academic Editors: Pirjo Mäkelä, Mercè Llugany, Peter A. Roussos and Mumtaz Cheema

Received: 1 December 2021

Accepted: 7 January 2022

Published: 14 January 2022

Publisher's Note: MDPI stays neutral with regard to jurisdictional claims in published maps and institutional affiliations.

Copyright: (C) 2022 by the authors. Licensee MDPI, Basel, Switzerland. This article is an open access article distributed under the terms and conditions of the Creative Commons Attribution (CC BY) license (https:// creativecommons.org/licenses/by/ $4.0 /)$.

\begin{abstract}
Sweet osmanthus (Osmanthus fragrans) is an evergreen woody plant that emits a floral aroma and is widely used in the landscape and fragrance industries. However, its application and cultivation regions are limited by cold stress. Heat-shock transcription factor (HSF) family members are widely present in plants and participate in, and regulate, the defense processes of plants under various abiotic stress conditions, but now, the role of this family in the responses of $O$. fragrans to cold stress is still not clear. Here, 46 OfHSF members were identified in the O. fragrans genome and divided into three subfamilies on the basis of a phylogenetic analysis. The promoter regions of most OfHSFs contained many cis-acting elements involved in multiple hormonal and abiotic stresses. RNA-seq data revealed that most of OfHSF genes were differentially expressed in various tissues, and some OfHSF members were induced by cold stress. The qRT-PCR analysis identified four OfHSFs that were induced by both cold and heat stresses, in which OfHSF11 and OfHSF43 had contrary expression trends under cold stress conditions and their expression patterns both showed recovery tendencies after the cold stress. OfHSF11 and OfHSF43 localized to the nuclei and their expression patterns were also induced under multiple abiotic stresses and hormonal treatments, indicating that they play critical roles in responses to multiple stresses. Furthermore, after a cold treatment, transient expression revealed that the malondialdehyde (MDA) content of OfHSF11-transformed tobacco significantly increased, and the expression levels of cold-response regulatory gene $N b D R E B 3$, cold response gene $\mathrm{NbLEA5}$ and ROS detoxification gene $\mathrm{NbCAT}$ were significantly inhibited, implying that OfHSF11 is a negative regulator of cold responses in O. fragrans. Our study contributes to the further functional characterization of OfHSFs and will be useful in developing improved cold-tolerant cultivars of $O$. fragrans.
\end{abstract}

Keywords: Osmanthus fragrans; heat-shock transcription factor; cold stress; abiotic and hormonal stresses

\section{Introduction}

Plant development and growth suffer from the effects of many environmental factors, like cold, heat, salinity and drought. Thus, many complex molecular regulatory mechanisms for resisting external stresses have evolved in plants. It is well known that a great number of transcription factors (TFs) genes involved in responding to abiotic stresses [1]. Members of the heat-shock transcription factor (HSF) family, as important regulatory elements in plants under stress conditions, function in stress-signaling pathways, signal transduction associated with protein kinase and other stress-related regulatory mechanisms [2]. What is more, the HSF family is also involved in the regulation of reactive oxygen species (ROS)-signaling pathway that is activated when plants are experiencing stress [3]. 
Normally, HSFs have several functional and structural features, including an Nterminal adjacent DNA-binding domain (DBD), nuclear export signal (NES), nuclear localization signal (NLS), oligomerization domain (OD or HR-A/B) and activator motifs (AHA motifs) [4]. HSFs in different species share a common typical structural feature, the DNA-binding domain, which contains four antiparallel stranded $\beta$-sheets and three helical bundles [5]. HSFs can be classified into three groups by the length of the amino acid (aa) residues inserted in the HR-A/B. The HR-A/B of the B-type HSFs are compact, whereas there are seven and 21 aa residues in the HR-A/B regions of the C- and A-type HSFs, respectively [6]. The NLSs of HSFs contain a domain composed of basic amino acid residues [7], and the NESs are mainly located at the C-termini of HSFs and are leucine-rich motifs. The synergistic effect of NLS and NES determines the subcellular localization of the HSF in different states [8]. The AHA motifs have transcriptional activation functions, and the number of AHA motifs in an HSF affects the activation activity [9]. The HSFs have been identified in many woody plants, such as Pyrus bretschneideri (29), Malus domestica (25) and Populus trichocarpa (31) [10-12]. However, the HSF family members of $O$. fragrans have not been identified.

The HSF family participates in plant regulatory processes under cold-stress conditions [13]. In Arabidopsis thaliana, the expression levels of AtHSFA6a, AtHSFA6b, AtHSFA9 and AtHSFC1 increase under $4{ }^{\circ} \mathrm{C}$ conditions [14]. In Triticum aestivum, the overexpression of TaHSF3 in A. thaliana increases its survival rate at $4{ }^{\circ} \mathrm{C}$, which confirmed that TaHSF3 enhances the cold tolerance of plants [15]. Remarkably, the cold stress can change membrane fluidity and increases rigidity of plant cell [16], and the membrane permeability directly reflects the degree of membrane injury, hence, the malondialdehyde (MDA) content indirectly indicates the degree of membrane damage [17]. The MDA has also been taken as a marker of reactive oxygen species-related plant injuries and has been used as a crucial indicator of cold tolerance [18]. In Musa acuminata, the lower MDA content in MaPIP2-7-overexpression plants indicated that they exhibit less membrane damage than wild-type plants under cold-stress conditions [19]. After a 6-h chilling stress, transgenic tobacco overexpressing $V a C B F 1$ from Vitis amurensis have significantly lower MDA contents compared with the control, demonstrating that $V a C B F 1$ enhances plant tolerance of cold stress [20]. To date, there are no reports of HSFs having negative regulatory roles under cold-stress conditions by increasing of the MDA content.

HSFs are involved in a variety of abiotic and hormonal stresses, especially the heat stress [21]. For instance, AtHSFA1a and AtHSFA1b play key roles in the early stages of heat-stress reactions [5]. Under salt-stress conditions, different HSF subclass members acted as positive or negative regulators. In Oryza sativa, the overexpression of OsHSFA2e in $A$. thaliana improves plant tolerance to salt stress [22]. However, the salt tolerance of japonica rice heterologously expressing $O s H S F B 2 b$ is reduced significantly [23]. HSFs are also important in plant tolerance to drought stress. Transgenic AtHSFA1b expressing $A$. thaliana grow well under $20 \%$ relative water content conditions, which indicated that AtHSFA1b is a positive regulator in plants experiencing drought stress [24]. Moreover, exogenous hormone treatments revealed that AtHSFA6b is involved in abscisic acid (ABA) signal transduction, and it is also an essential TF for ABA-mediated heat-stress tolerance [23].

Osmanthus fragrans is an important ornamental and economic woody plant that is widely used in landscaping; however, its application range is greatly limited by cold weather [25]. Studies of $O$. fragrans have been mainly concerned with fragrance and petal color, and there are also some physiological research on the tolerance of $O$. fragrans to different stresses [26-29]. However, the molecular regulatory mechanisms of $O$. fragrans involved in low-temperature responses are still unclear [30]. In this study, 46 HSF family genes were identified in the $O$. fragrans genome, and their phylogenetic relationships, motifs and gene structures were characterized. We also explored the expression profiles of OfHSFs in different tissues and under cold-stress conditions. Additionally, the expression patterns of candidate OfHSFs in response to multiple stress treatments were compared. Furthermore, the cold-tolerance function of OfHSF11 was assessed using the MDA content 
in transiently transformed tobacco. These results provide new information on the functions of OfHSFs and provide useful genetic resources for $O$. fragrans varietal improvement.

\section{Materials and Methods}

\subsection{Genome-Wide Identification of OfHSFs in O. fragrans}

The genome sequence data of $O$. fragrans were acquired from the $O$. fragrans genomic [31], and the hidden Markov model of the HSF family was downloaded from the protein database Pfam (http://pfam.xfam.org/, PF00447, accessed on 28 March 2020). The candidate OfHSF members of $O$. fragrans were found using hmmer 3.0 software (E-value $<1 \times 10^{-5}$ ). Three online tools, SMART (http://smart.embl-heidelberg.de, accessed on 7 May 2020), Batch CD-search (https: / /www.ncbi.nlm.nih.gov/Structure/bwrpsb / bwrpsb.cgi, accessed on 29 March 2020) and Pfam (http:/ / pfam.xfam.org/, accessed on 1 May 2020) were used to examine whether the HSF conserved domains were entire, and those candidate gene sequences with missing conserved sites were deleted. MARCOIL (https:/ / toolkit.tuebingen.mpg.de/tools/marcoil, accessed on 6 September 2021) was used for predicting coiled-coil domains. The relative molecular mass, theoretical isoelectric point, amino acid residues with the ExPASy website (http:/ / web.expasy.org/compute_pi, accessed on 19 June 2020) were used to calculate the hydrophilicities of OfHSF protein sequences. Additionally, the lengths of nuclear and amino acids sequences were obtained using TBtools [32].

\subsection{Integrated Analyses of Gene Structure, Motif Distribution and Phylogenetic Evolution of OfHSFs}

The protein sequences of OfHSF members were extracted from $O$. fragrans genomic database. The HSF protein sequences of $A$. thaliana (21), P. bretschneideri (29) and P. trichocarpa (30) were downloaded from TAIR (https: / / www.arabidopsis.org/, accessed on 31 July 2020) and PlantTFDB (http:/ / planttfdb.gao-lab.org/, accessed on 26 September 2021) [10,12]. The HSF protein sequences were compared using MUSCLE in the MEGA11 software [33]. The default parameters were used to construct the phylogenetic tree of HSF members in O. fragrans, A. thaliana, P. bretschneideri and P. trichocarpa by the Neighbor-joining method. The analysis of gene structure (exon/intron distribution) of HSF family members was conducted using the genome annotation of $O$. fragrans and visualized using Circle Gene View in TBtools software [32]. The conserved motifs of OfHSFs were analyzed using MEME online software (http:/ / meme-suite.org/tools/meme, accessed on 20 July 2021) [34]. TBtools software was used to visualize the gene structure, motif distribution and phylogenetic relationships of OfHSF members.

\subsection{Chromosomal Locations and Gene Duplications of OfHSF Genes}

Using the GFF3 file, the corresponding chromosomal locations of OfHSFs were acquired using TBtools software [32]. The OfHSF duplication events were analyzed using the Multiple Collinearity Scan toolkit (MCScanX) [35]. The results were analyzed and visualized using Super Circos in TBtools.

\subsection{OfHSF Promoter Cis-Acting Elements Analysis}

The 2000-bp sequences located upstream of the OfHSFs' initial codons were obtained from the $O$. fragrans genomic database and submitted to PlantCARE online prediction website (https: / / bioinformatics.psb.ugent.be/webtools/plantcare/html, accessed on 22 September 2021) for a cis-acting element analysis [36].

\subsection{Expression Profiles of OfHSFs as Assessed by RNA-Seq}

The raw counts of HSF members of $O$. fragrans in four tissues and three flowering stages were obtained from our previous $O$. fragrans ('Rixianggui') transcriptome data (Table S1), it has been uploaded in NCBI (SRP143423) [31]. The transcription levels of each OfHSF member in leaves under cold stress conditions at 0,3,12, 24, 72 and $120 \mathrm{~h}$, as well as 
$72 \mathrm{~h}$ after recovery, were calculated using raw counts from RNA-seq data (Table S2). The raw counts were converted to $\log _{10}$, and the expression level of each OfHSF was visualized in a heatmap constructed using TBtools.

\subsection{Plant Materials and Stress Treatments}

Two-year-old cutting-based seedlings of $O$. fragrans ('Rixianggui') with relatively consistent growth were selected from a greenhouse at Nanjing Forestry University. Before the cold treatment, the selected seedlings were placed in a growth chamber under conditions of 16 - / 8-h light/dark at $23 / 22{ }^{\circ} \mathrm{C}$, with a $250 \mathrm{umol} \cdot \mathrm{m}^{-2} \mathrm{~s}^{-1}$ light intensity and $60 \%$ relative humidity, for one week. In total, $42 \mathrm{O}$. fragrans seedlings were selected for the cold-stress treatment at $4{ }^{\circ} \mathrm{C}$, and they were sampled at $0,3,12,24,72$ and $120 \mathrm{~h}$ during the treatment and at $72 \mathrm{~h}$ after recovery. Moreover, $18 \mathrm{O}$. fragrans seedlings were treated at $42{ }^{\circ} \mathrm{C}$ and sampled at 0,6 and $24 \mathrm{~h}$. Another $24 \mathrm{O}$. fragrans plants were treated under salt-stress conditions by culturing in $200 \mathrm{mM} \mathrm{NaCl}$ solution and sampled at $0,6,24$ and $72 \mathrm{~h}$. Another 24 plants were subjected to waterlogging stress by keeping the pot water level overflowing, and 24 plants were subjected to drought stress using a 20\% PEG600 solution. These plants were sampled at the same time as the plants subjected to salt stress. Additionally, 54 O. fragrans seedlings were each subjected independently to ABA $\left(100 \mu \mathrm{mol} \cdot \mathrm{L}^{-1}\right.$, leaf spraying), methyl-jasmonate (MeJA) $\left(100 \mu \mathrm{mol} \cdot \mathrm{L}^{-1}\right.$, leaf spraying) and gibberellin $\left(\mathrm{GA}_{3}\right)$ (50 $\mathrm{mol} \cdot \mathrm{L}^{-1}$, leaf spraying) and sampled at 0,6 and $24 \mathrm{~h}$. The overview of stress treatments of $O$. fragrans is shown in Table S3. The first two pairs of leaves were sampled as a biological replicate. The samples collected from $O$. fragrans seedlings without any treatment were used as controls. Liquid nitrogen was used to immediately freeze the collected samples, and then, they were transferred to $-80^{\circ} \mathrm{C}$ refrigerator for storage prior to RNA extraction. Three biological replicates were performed per treatment time point, and each sample was collected from two independent plants.

\subsection{RNA Extraction and Quantitative Real-Time PCR ( $q R T-P C R)$ Analyses}

Total RNA was isolated using an EASYspin Plus kit (Aidlab, Beijing, China), the gDNA was removed, and the RNA was transcribed into cDNA using Trans-Script OneStep gDNA Remover and cDNA Synthesis SuperMix (Transgen, Beijing, China). The resulting cDNA was diluted 20-fold with $\mathrm{ddH}_{2} \mathrm{O}$ for qRT-PCR assays [37]. The analysis of HSF gene expression in $O$. fragrans under cold-treatment conditions resulted in the selection of five OfHSFs. Primer Premier 5 software was used to design specific primers for candidate genes [38]. Moreover, the designed primers were submitted to NCBI PrimerBLAST (https:/ / www.ncbi.nlm.nih.gov/tools/primer-blast/, accessed on 11 August 2021) to use them as query in BLAST searches against genome sequences to ensure their specificity (Table S4). The qRT-PCR was carried out in accordance with a previous method [39]. OfRAN was selected as the normalized internal reference gene [40]. The relative expression levels of candidate OfHSFs were calculated using the $2^{-\Delta \Delta C T}$ method [41]. Three biological replicates and three technical replicates were performed, and the significant differences were evaluated using SPSS 24 with Duncan's test at the 0.01 level.

\subsection{Transient Overexpression of OfHSF11 and OfHSF43 in Tobacco for Subcellular Localization and Cold-Stress Biochemical Analysis}

The full-length cDNAs of OfHSF11 and OfHSF43 were inserted independently into the pCAMBIA Super 1300-GFP vector using the SmaI and SpeI restriction sites to construct 35S::GFP-OfHSF11 and 35S::GFP-OfHSF43, respectively. The corresponding OfHSFs-GFP plasmid and empty vector (EV) transformed independently into Agrobacterium tumefaciens (GV3101) were infiltrated into tobacco (Nicotiana benthamiana) leaves for transient expression to observe the subcellular localizations of the two genes. After transformation, the tobacco plants were grown for 2 days at $22 / 21{ }^{\circ} \mathrm{C}$ and $60 \%$ relative humidity under a $16-/ 8$-h light/dark photoperiod. Then, fluorescence signals in some plants were observed using a LSM710 microscope (Zeiss, Jena, Germany). Semi-quantitative RT-PCR was used to verify 
whether the target gene was expressed in transient transformation plants. The rest of transient transformation tobacco plants were treated at $4{ }^{\circ} \mathrm{C}$ for $6 \mathrm{~h}$ in a growth chamber, and the MDA contents of three biological replicates were measured. The MDA content was detected using the thiobarbituric acid colorimetric method [19]. After cold treatment of the OfHSF11 and OfHSF43 transient expression plants, some candidate functional genes (NbAPX, NbCAT, NbSOD, NbDREB3, NbLEA5, NbHSP70 and NbHSP90) which have been confirmed that related to ROS detoxification and stress responses were selected for qRTPCR [42,43]. The primers used for clone and RT-PCR of the genes (OfHSF11 and OfHSF43) are listed in Table S4.

\section{Results}

\subsection{Genome-Wide Identification and Analysis of the HSF Gene Family in O. fragrans}

A total of 46 OfHSF genes, assigned OfHSF1-46 in accordance with the chromosomal location, were identified in O. fragrans (Figure S1). The lengths of these HSF genes vary widely from 615 (OfHSF3) to $1713 \mathrm{bp}$ (OfHSF44), and these two members encode proteins of 204 and 570 aa, respectively. The predicted isoelectric points vary from 4.64 (OfHSF41) to 9.52 (OfHSF20). The relative molecular weights of these HSF proteins range from 22.94 (OfHSF3) to 62.52 (OfHSF44) kDa. Additional information on the 46 OfHSFs are presented in Table S5.

\subsection{Phylogenetic Analysis, Intron-Exon Structures and Conserved Motifs of OfHSF Proteins}

A phylogenetic tree was constructed to evaluate the evolutionary relationships of the HSF proteins of $O$. fragrans, A. thaliana (dicotyledonous model plant) and other two woody plants species $P$. bretschneideri and $P$. trichocarpa (Figure 1). Based on the phylogenetic relationships and characteristics of the HR-A/B domain, the OfHSFs were divided into three groups (A, B and C). A total of 27 OfHSFs belong to subfamily A, with the others being divided into subfamily B (15) and subfamily C (4) (Figure 2a). Although subfamily C contains only four OfHSFs, O. fragrans has more subfamily members than the other three dicotyledonous plants.

The sequences of the OfHSF proteins were submitted to the MEME website to analyze the distribution of its protein motifs, and 15 conserved motif distributions in the 46 OfHSF proteins were successfully generated (Figure $2 \mathrm{~b}$ ). All of the OfHSF proteins contain motifs 1 and 5. Moreover, OfHSF10, $-17,-18$ and -26 in the $C$ subfamily have similar motif and gene structures. However, some motifs were detected specifically in certain subfamilies. For instance, motif 13 was identified only in the $C$ subfamily, and motifs $6,8,10,11,12$ and 14 only existed in the A subfamily. Additionally, motif 15 was only identified in the B subfamily. The members within phylogenetic tree branches have similar motif structures (Figure 2). To determine more information on the structural diversity of the OfHSF genes, we compared the full-length cDNA and corresponding genomic DNA sequences. In total, 40 of OfHSF genes have only one intron, and the other members have two (OfHSF7, -10 , $-31,-34$ and -35 ) or more introns (OfHSF12) (Figure 2c). 


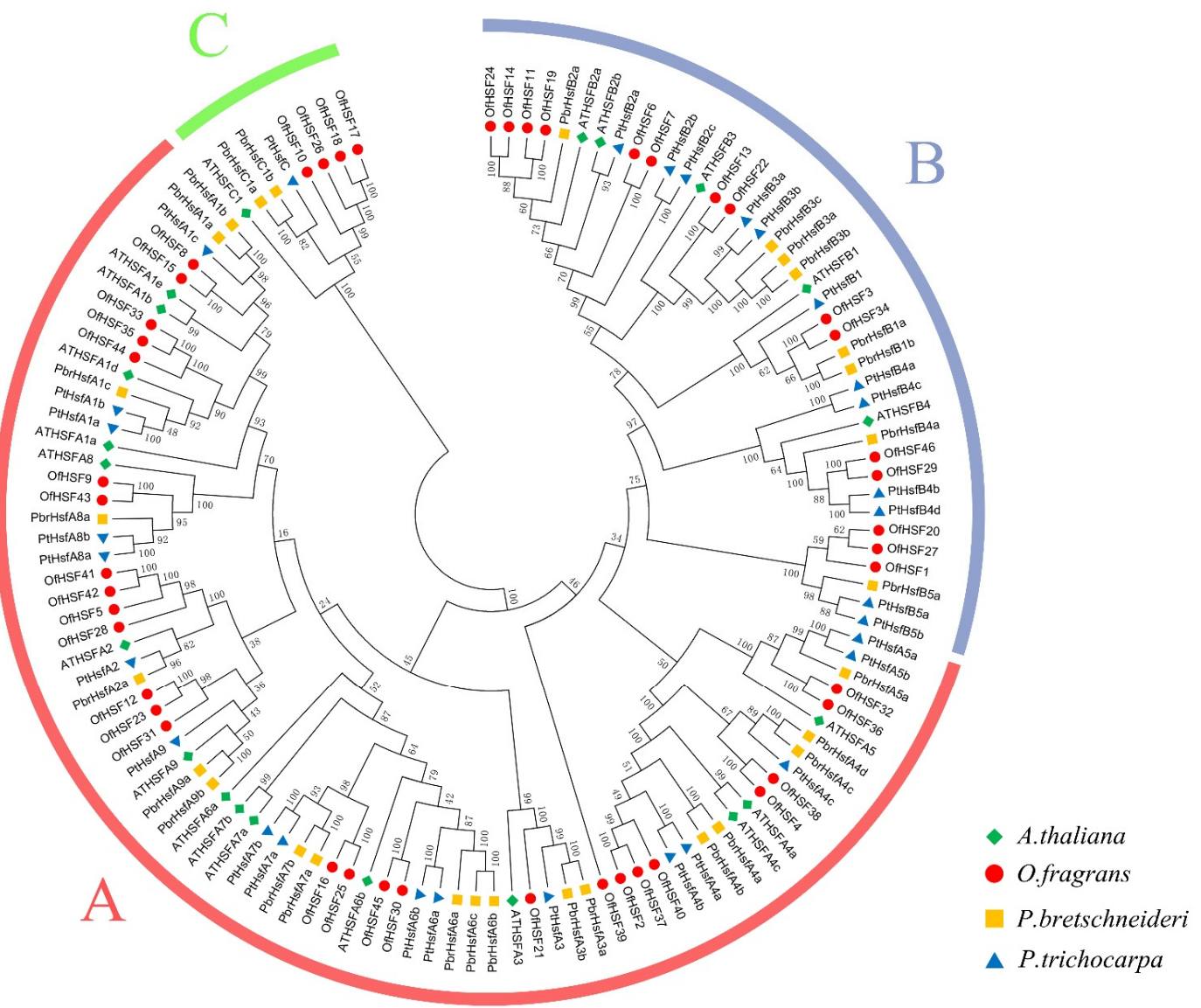

Figure 1. Phylogenetic tree of HSF family members from O. fragrans (Of), A. thaliana (At), P. bretschneideri $(\mathrm{Pb})$ and P. trichocarpa $(\mathrm{Pt})$. Phylogenetic relationships were constructed using MEGA11 with the Neighbor-joining method. The OfHSFs were divided into A, B and C subfamilies and represented by with different colors.

a

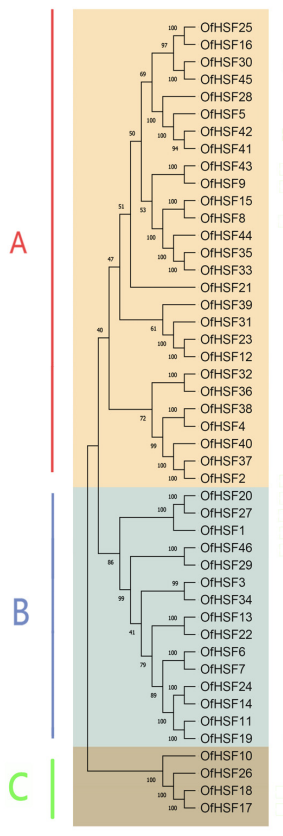

$\mathrm{b}$

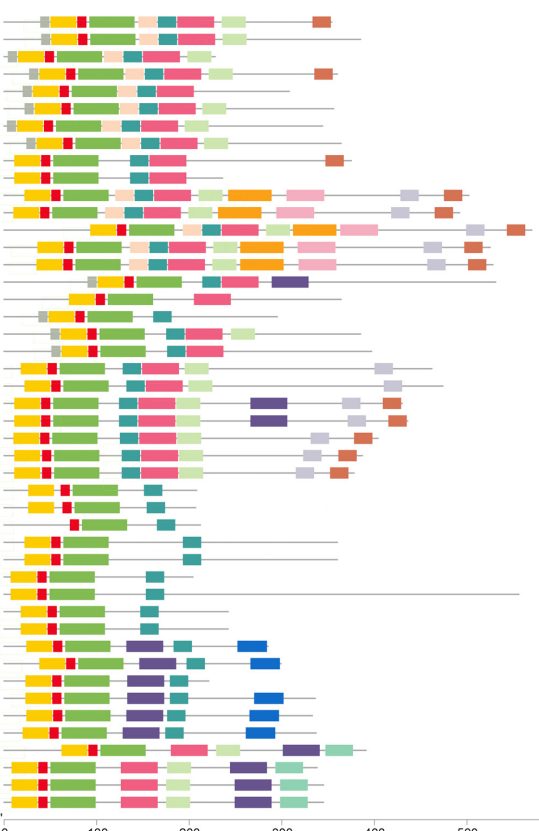

$\mathrm{c}$

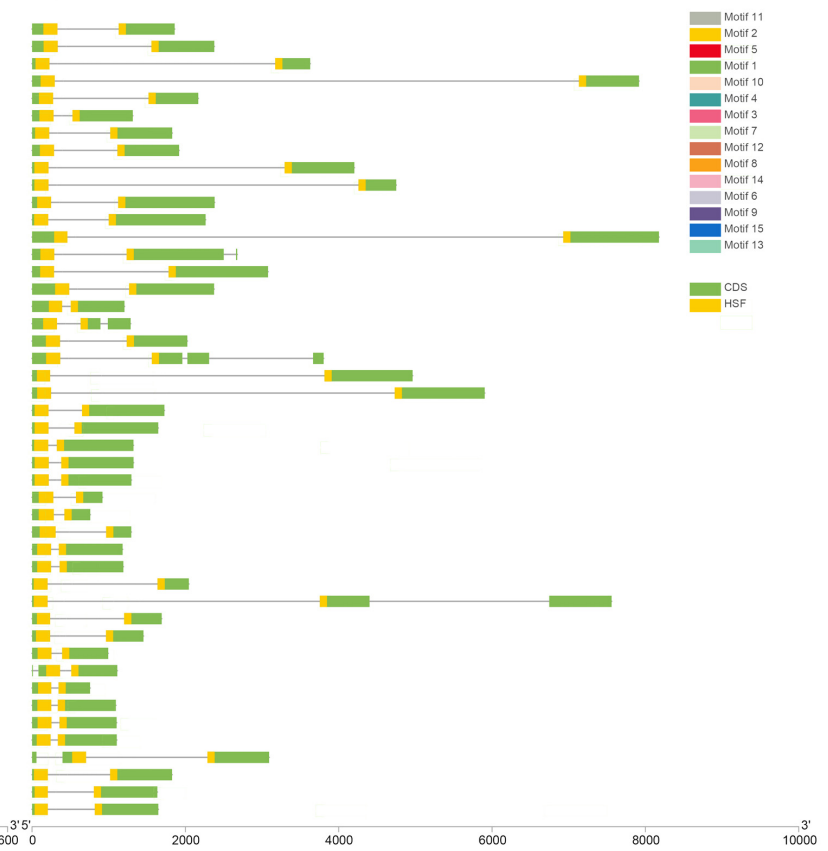

Figure 2. Phylogenetic tree, conserved motif distribution and gene structures of the of OfHSF genes. (a) The phylogenetic tree of OfHSF protein sequences was constructed using MEGA11 software, and 
the family was classified into the A, B and C subfamilies, which are represented by different colors. (b) Conserved motif distribution in the OfHSF proteins. Different motifs are denoted by different numbers and colors. (c) The exon-intron distributions of OfHSFs are shown with exons represented by green wedges and introns represented by black lines. The conserved domains of OfHSF family are represented by yellow wedges.

\subsection{OfHSF Promoter Cis-Acting Element Analysis}

To further investigate the potential functions of OfHSFs, the promoter regions of OfHSF genes were submitted to the PlantCARE online website for cis-acting element prediction (Table S6). A total of 35 cis-acting elements were identified, including 10 hormone response-, 7 stress response- and 8 light response-related elements as well as 10 developmental regulatory elements (Figure 3 ). The hormones related to the response elements include ABA, GA, IAA, MeJA and SA. Most of the OfHSFs contain different numbers of cis-acting elements related to ABA- and MeJA-responsiveness. In addition, the cis-acting elements are involved in abiotic stress responses, including drought, low-temperature, heat stress, wound and anaerobic induction. The stress response-related cis-acting elements are mainly related to anaerobic induction, drought and cold. Interestingly, only OfHSF5 contains a heat-responsiveness cis-acting element. The promoter regions of the OfHSFs contain many light-responsive elements, including Box 4, GT1-motif, AE-box, G-box, ATCT-motif, TCT-motif, MRE and GATA-motif. In total 10 OfHSFs have cis-acting regulatory elements that are involved in circadian control.

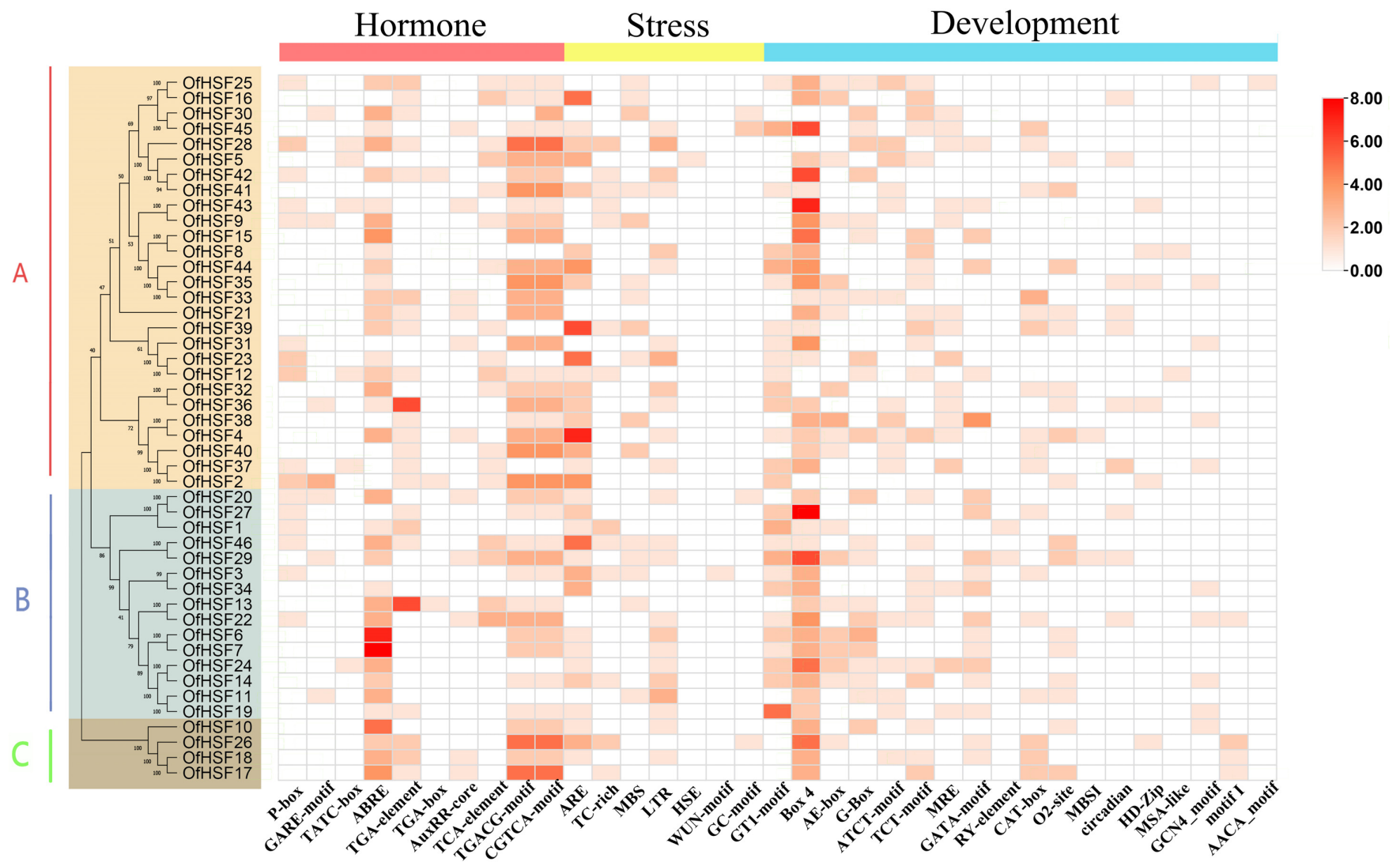

Figure 3. The cis-regulatory elements in the promoter regions of OfHSFs. The red histogram on the right of heat map indicates the corresponding number of cis-regulatory element. The red, yellow and blue rectangles represent three types of the cis-acting elements related with hormone, stress and development, respectively. The OfHSFs were divided into A, B and C subfamilies and represented by with different colors. 


\subsection{Chromosomal Location and Synteny Analysis of OfHSF Genes}

The 46 OfHSF genes were located on 17 chromosomes, with an uneven distribution, ranging from one to seven per chromosome, according to an analysis of the genome annotation data (Figure 4). The largest number of OfHSF genes are located on $\mathrm{Chr02,}$ however, Chr13, Chr15 and Chr18 each contain only one OfHSF gene. In this study, there was a pair of tandem duplicated genes identified (OfHSF41/42). Moreover, 65 segmental duplication pairs contained in 41 OfHSF genes were identified (Figure S2).
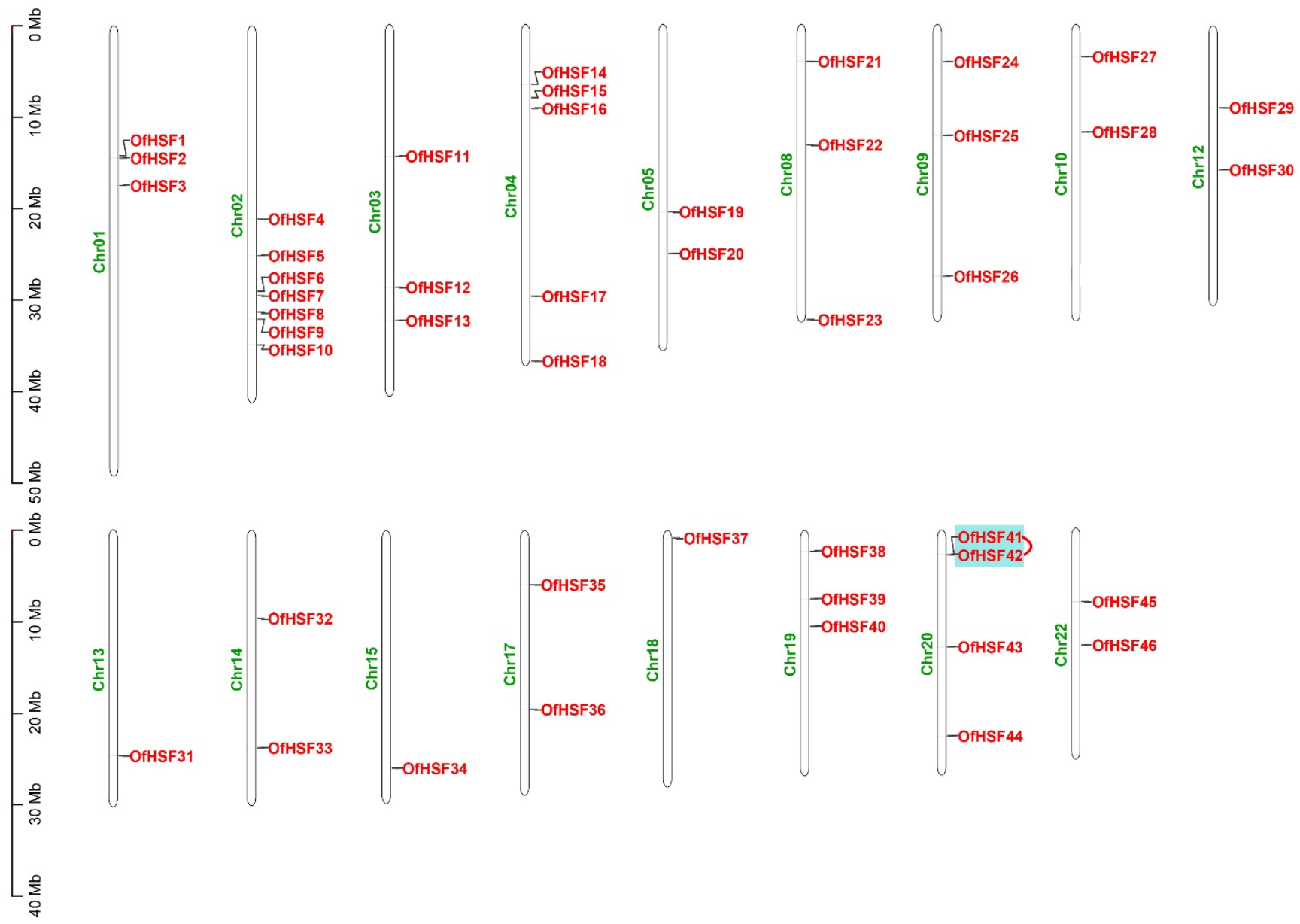

Figure 4. Distribution of OfHSFs on the chromosomes of $O$. fragrans. The scale on the left side of the picture is in million bases $(\mathrm{Mb})$. The chromosomal numbers are shown to the left of each chromosome. The blue rectangle represents the tandem duplication.

\subsection{Expression Profiles of OfHSF Genes in Different Tissues}

The heatmap revealed that 42 OfHSFs were expressed in four tissues and several developmental stages, and four genes showed no expression (Figure 5a). The expression levels of most OfHSF genes having more than one intron were less than those members having only one intron. OfHSF45 was expressed specifically in the root. OfHSF16 and -28 were expressed in mature leaves and the primary blooming stage. Except OfHSF1, $-16,-23,-27,-28$ and -45 , the other OfHSFs were detected in all tissues. According to the evolutionary tree, some OfHSFs on close branches shared similar gene expression patterns. The number of OfHSFs with raw counts $>100$ in all tissues and stages was $12(26.1 \%)$. Among these OfHSFs, OfHSF34 had remarkably increased expression levels during the flower full blooming and fading stages. The expression of OfHSF13 in the root is significantly higher than that in other tissues. Unlike its expression level in other tissues, OfHSF11 maintained comparatively high expression levels in three flower blossom stages. 
The expression levels of five OfHSFs (OfHSF13, -18, -19, -24 and OfHSF36) in mature leaves increased significantly compared with in young leaves, with an average of four times rise.

a

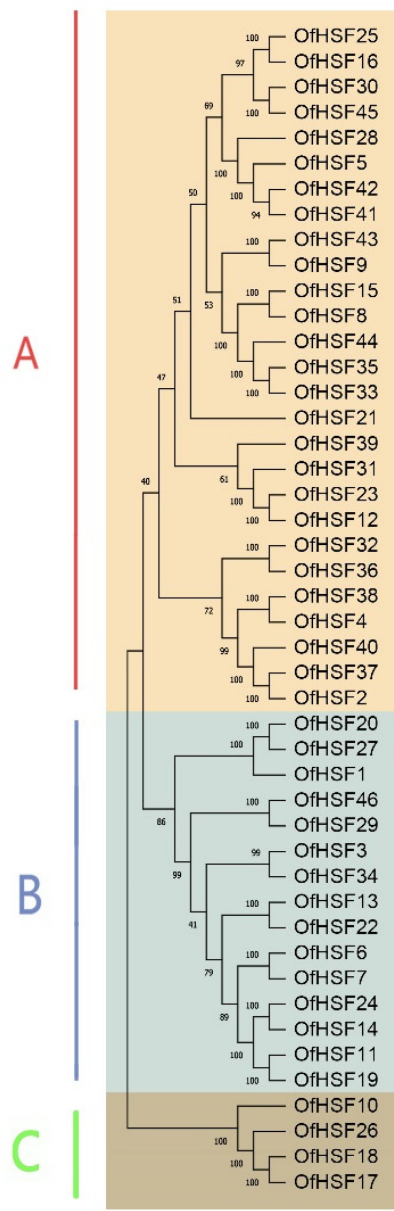

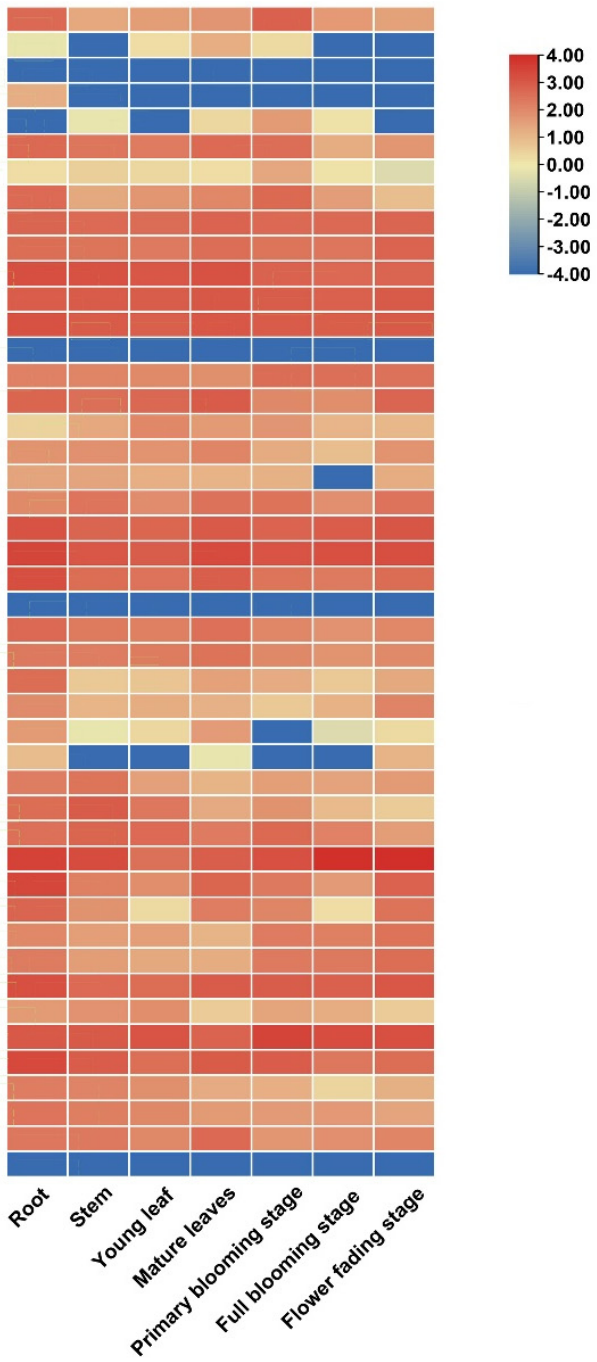

b

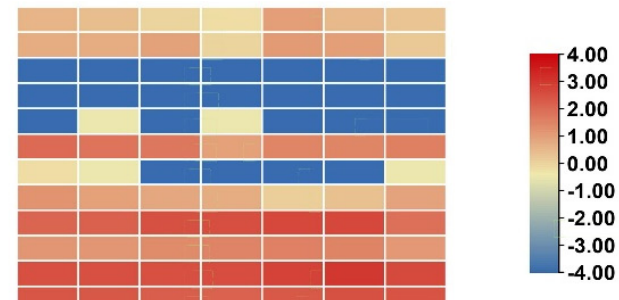

Figure 5. Clustering expression analysis of 46 OfHSFs in seven tissues (a) and in response to cold stress (b). C0 h, C3 h, C12 h, C24 h, C72 h and C120 h denote the different cold treatment times. The Cr72 h denotes recovery for $72 \mathrm{~h}$ after a 5 - $\mathrm{d}$ cold treatment. The raw counts of OfHSFs were transformed to $\log _{10}$ (value +0.0001 ). The colored histogram on the right of each heat map indicates the corresponding expression levels. The OfHSFs were divided into A, B and C subfamilies and represented by with different colors.

\subsection{Expression Patterns of OfHSF Genes in Response to Cold Stress}

The expression levels of OfHSFs in response to cold stress were analyzed using RNAseq data from $O$. fragrans subjected to a low temperature treatment for different periods. All the OfHSFs had different expression patterns (Figure 5b). As is shown in a heatmap, the expression of OfHSF30 was not observed in different $O$. fragrans tissues and after different cold-treatment periods. The number of OfHSFs with raw counts $<100$ during all the cold-treatment stages was $22(47.8 \%)$.

After a 3-h $4{ }^{\circ} \mathrm{C}$ treatment, most OfHSFs showed no obvious changes; however, the expression levels of $O f H S F 21$ was up-regulated for about two times in this stage. Its expression maintained an overall increasing tendency for $72 \mathrm{~h}$ and then decreased to the pre-treatment level. The expression profiles of OfHSFs under cold-stress conditions were 
summarized into three general patterns. The expression levels of some OfHSFs continued increasing until $72 \mathrm{~h}$ and then gradually declined, with turning points at $72 \mathrm{~h}$ (OfHSF4, $-9,-10,-40$ and -43$)$ or $120 \mathrm{~h}$ (OfHSF15, -26 and -35). On the contrary, the expression levels of other OfHSFs first decreased and then increased, with the turning point being predominantly $120 \mathrm{~h}$ (OfHSF3, -6, -7, -11,-12,-34 and -44), although some turned at $24 \mathrm{~h}$ (OfHSF8 and OfHSF17) and $72 \mathrm{~h}$ (OfHSF18 and -37). Unlike the above two change patterns, two subgroups showed other expression variations. The expression levels of OfHSF32 and OfHSF36 showed a downward trend at the initial stage of induction, but suddenly increased at $24 \mathrm{~h}$ and $72 \mathrm{~h}$, respectively. They then decreased for the next period and peaked at $72 \mathrm{~h}$ after recovery. Similarly, members of another subgroup, which contained OfHSF14, -19 and -24 , showed initial decreased expression levels until $24 \mathrm{~h}$, increased to peaks at $120 \mathrm{~h}$ and finally decreased to pre-treatment levels after $72 \mathrm{~h}$ of recovery (Figure $5 \mathrm{~b}$ ).

\subsection{The qRT-PCR Analysis of Five Candidate OfHSFs under Cold-and Heat-Stress Conditions}

Five cold-related OfHSF genes were selected on the basis of their responses to different cold-treatment periods at $4{ }^{\circ} \mathrm{C}$. To verify the observed expression levels of these cold-related OfHSFs, they were quantitatively analyzed by qRT-PCR. The results were approximately consistent with the RNA-seq data, indicating that the expression analysis obtained by the latter are reliable (Figure 6b). Their expression levels were analyzed at seven consecutive time points, $0,3,12,24,72$ and $120 \mathrm{~h}$, after a cold treatment, as well as $72 \mathrm{~h}$ after recovery. OfHSF15 and OfHSF43 showed the tendency of initial increased expression and then decreasing, with the highest expression levels being at $120 \mathrm{~h}$ and $72 \mathrm{~h}$, respectively. OfHSF35 was up-regulated continuously during the cold-stress treatment. The expression of OfHSF4 did not change significantly (Figure 6a). Compared with the expression levels of the above four OfHSFs, that of OfHSF11 showed a different trend of continuously decreasing, before increasing at $72 \mathrm{~h}$ after recovery. Notably, the expression levels of OfHSF11 and OfHSF43 in the recovery period approached those of the pre-treatment period.

In addition, we investigated the expression patterns of these five OfHSFs under heatstress conditions at $42{ }^{\circ} \mathrm{C}$. The expression levels of OfHSF4, -35 and -43 continued increasing during the high temperature-treatment period (Figure 6c). OfHSF11 and OfHSF15 were down-regulated at $6 \mathrm{~h}$; however, there were no significant differences between their expression levels before treatment and at $24 \mathrm{~h}(p<0.01)$. Among these five cold-induced candidate OfHSFs, OfHSF43 was significant induced by heat stress. 
a

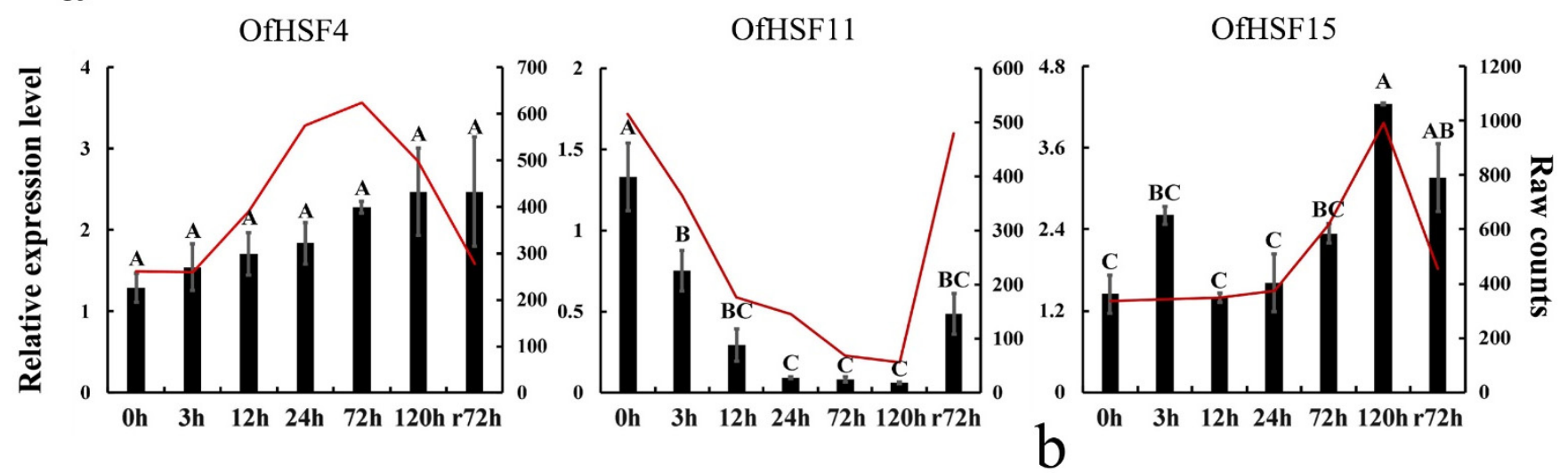

OfHSF35

\section{OfHSF43}
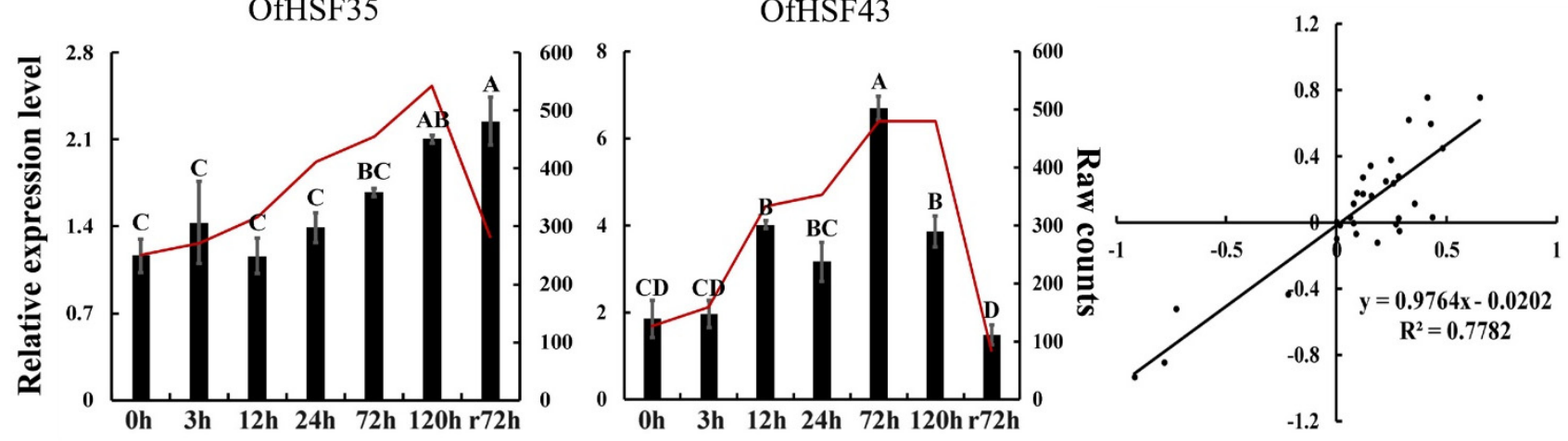

C

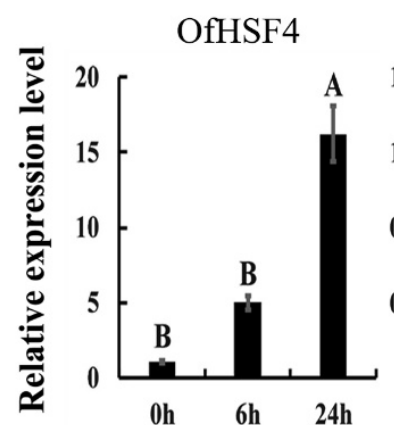

OfHSF11

OfHSF 15

OfHSF35

OfHSF43
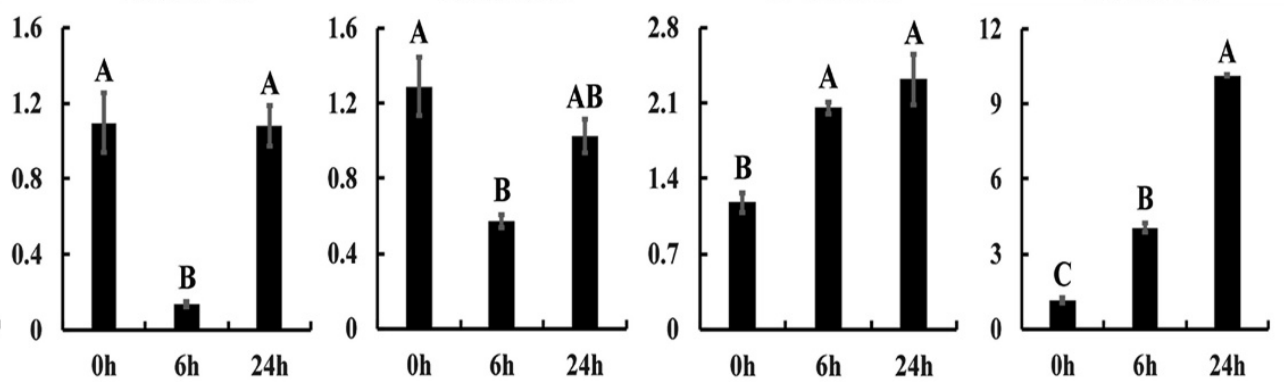

Figure 6. Expression profiles of the five selected OfHSF genes in response to stresses. (a) The relative expression levels of five selected OfHSF genes under cold-stress conditions. Black columns represent the qRT-PCR results and red lines represent raw counts. The error bars indicate the means \pm SEs $(n=3)$. Capital letters represent the significant differences as assessed by Duncan's test at the 0.01 level. (b) Correlation analysis between the raw counts and qRT-PCR results. The black line represents the correlation trend line. (c) The relative expression levels of five selected OfHSF genes under heat-stress conditions.

\subsection{OfHSF11 and OfHSF43 Are Induced by Different Stresses}

On the basis of the above cis-acting element analysis and the expression patterns of the five selected OfHSFs under cold-stress conditions (Figures 3 and 6), OfHSF11 and OfHSF43, which had expression trends that showed significant decreases/increases, were selected for further analyses. The expression level of OfHSF11 showed a down-regulation trend during the initial stages at $6 \mathrm{~h}$ after waterlogging and drought treatments, peaked at $24 \mathrm{~h}$ and then were again down-regulated at $72 \mathrm{~h}$ during the waterlogging stress. OfHSF11 was significantly induced at $72 \mathrm{~h}$ in response to salt stress (Figure 7a). Expression patterns revealed that OfHSF43 was significantly inhibited under both waterlogging and drought 
conditions. The expression of OfHSF43 increased significantly and peaked at $6 \mathrm{~h}$ during the salt treatment. It then decreased continuously.

a

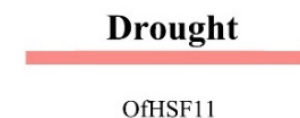

OfHSF11

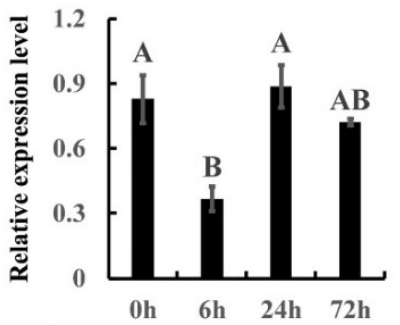

OfHSF43

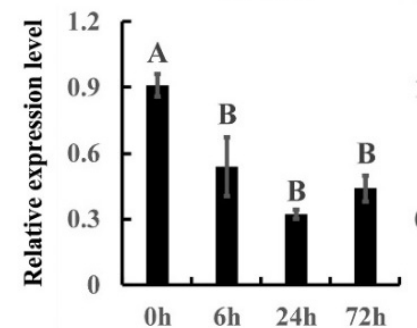

b

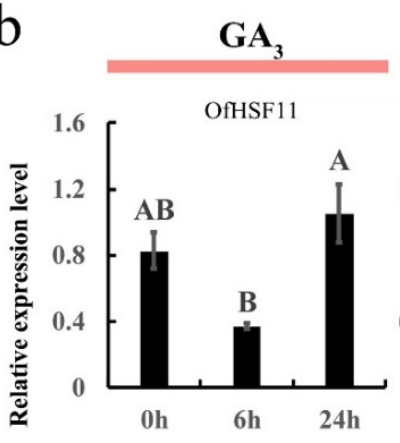

OfHSF43

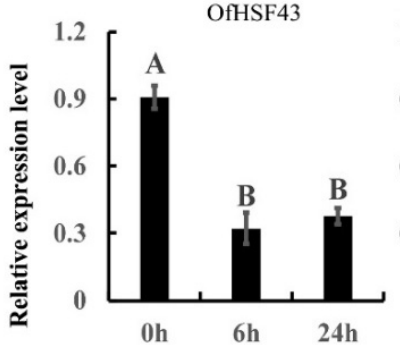

Salt

OfHSF11

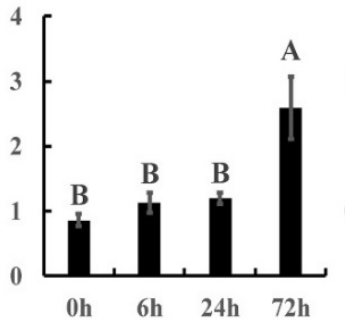

OfHSF43

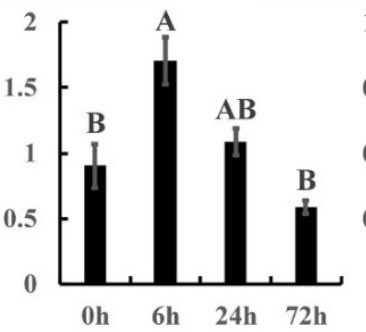

ABA

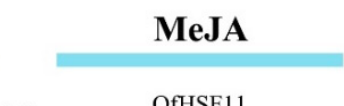

OfHSF11

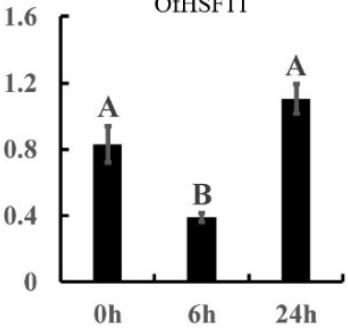

OfHSF43
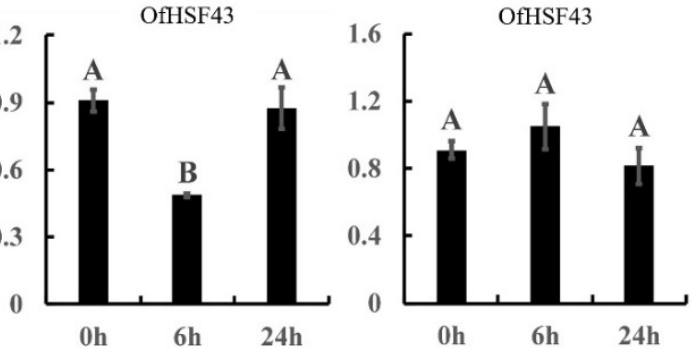

Figure 7. Expression patterns of OfHSF11 and OfHSF43 in response to multiple abiotic stresses (a) and exogenous hormonal treatments $(\mathbf{b})$. The error bars indicate the means \pm SEs $(n=3)$. Capital letters represent the significant differences as assessed by Duncan's test at the 0.01 level.

OfHSF11 had similar expression patterns in response to three different hormone treatments. Its expression levels decreased at $6 \mathrm{~h}$ and then returned to slightly higher than pre-treatment levels at $24 \mathrm{~h}$, indicating that OfHSF11 responded similarly to the hormonal treatments (Figure $7 \mathrm{~b}$ ). The expression of OfHSF43 decreased at $6 \mathrm{~h}$ in response to ABA and $\mathrm{GA}_{3}$, and then, the expression returned to the pre-treatment level in response to ABA. However, the expression level of OfHSF43 showed no significant changes in response to MeJA. 


\subsection{OfHSF11 and OfHSF43 Are Localized in the Nuclei}

To assess the potential functions of OfHSF11 and OfHSF43 in transcriptional regulatory systems, the subcellular localizations of 35S::GFP-OfHSF11/OfHSF43 were observed in tobacco ( $N$. benthamiana) leaves. The green fluorescence signals of 35S::GFP were observed in both the plasma membrane and nuclei, whereas the GFP fluorescence signals of 35S::GFPOfHSF11 and 35S::GFP-OfHSF43 were mainly located in the nuclei (Figure 8).
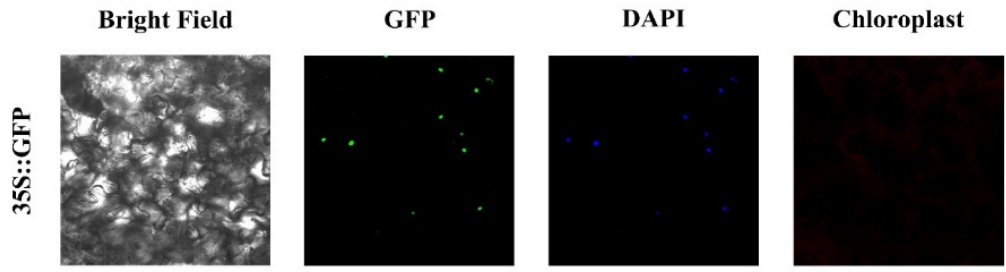

Merged
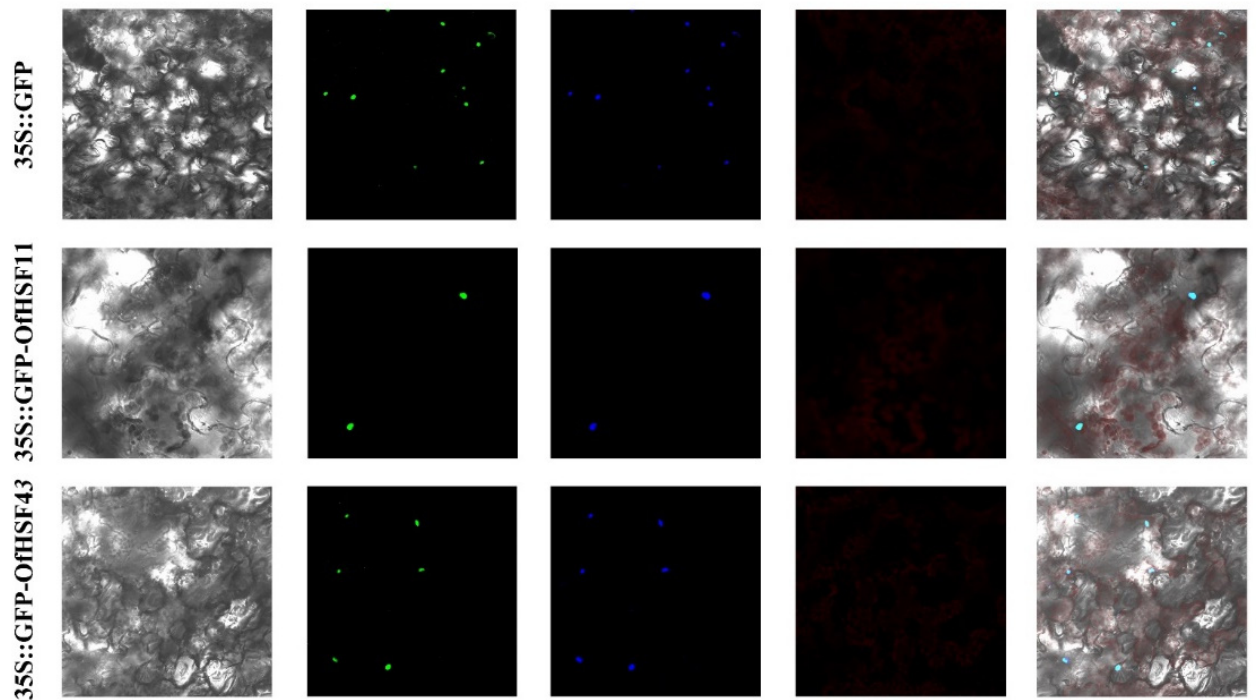

Figure 8. Subcellular localizations of OfHSF11 and OfHSF43. GFP represents the vector control. DAPI staining was used to mark the positions of nuclei.

\subsection{Overexpression of OfHSF11 in Tobacco Resulted in Increased Cold Sensitivity and Changed Expression Level of Stress-Related Genes}

Transient transformation of tobacco was performed to investigate the roles of OfHSF11 and OfHSF43 in response to cold stress. OfHSF11 and OfHSF43 were independently transiently transformed into tobacco, which was confirmed by a semi-quantitative RT-PCR analysis (Figure 9b). The repeated gel image for semi-quantitative RT-PCR analysis of Nbactin in transiently transformed tobacco was shown in Figure S3. Thus, we measured the MDA contents of the leaves from transgenic tobacco plants under low-temperature conditions. Compared with the empty vector (EV), cold stress induced significant increases in the MDA contents of leaves from the 35S::GFP-OfHSF11 transformed plants; however, there were no significant differences in the MDA contents from 35S::GFP-OfHSF43 transformed plants compared with the EV (Figure 9a).

To further understand the molecular mechanisms of decreased cold tolerance in OfHSF11-overexpression tobacco, the expression levels of three ROS detoxification genes ( $\mathrm{NbAPX}, \mathrm{NbCAT}$ and $\mathrm{NbSOD}$ ), three stress-response genes (NbLEA5, NbHSP70 and NbHSP90) and a cold stress regulatory gene (NbDREB3) were examined after exposure to cold stress. The transcript levels of $N b C A T, N b D R E B 3$ and $N b L E A 5$ were significantly lower in OfHSF11overexpression plants than the EV (Figure 9c). Though the expressions of these genes also showed significant decrease in OfHSF43-overexpression plants, these differences were not so obvious compared with those under transient expressions of OfHSF11 (Figure 9d). Notably, the expression of $\mathrm{NbCAT}$ decreased nearly 10 times in OfHSF11-overexpression plants compared with the EV after the cold treatment. On the contrary, the transcript level of NbHSP70 was significantly upregulated under both transient expressions of OfHSF11 and OfHSF43 compared with the EV. The expression of $N b S O D$ was significantly higher in OfHSF11-overexpression plants; however, showed no more significant change in OfHSF43overexpression plants than EV. Besides, the transcript level of NbAPX was significantly 
up-regulated in OfHSF43-overexpression plants, while no significant change in OfHSF11overexpression plants than EV. There was no significant difference in the expression of NbHSP90 between both 35S::GFP-OfHSF11/OfHSF43 transformed plants and the EV.
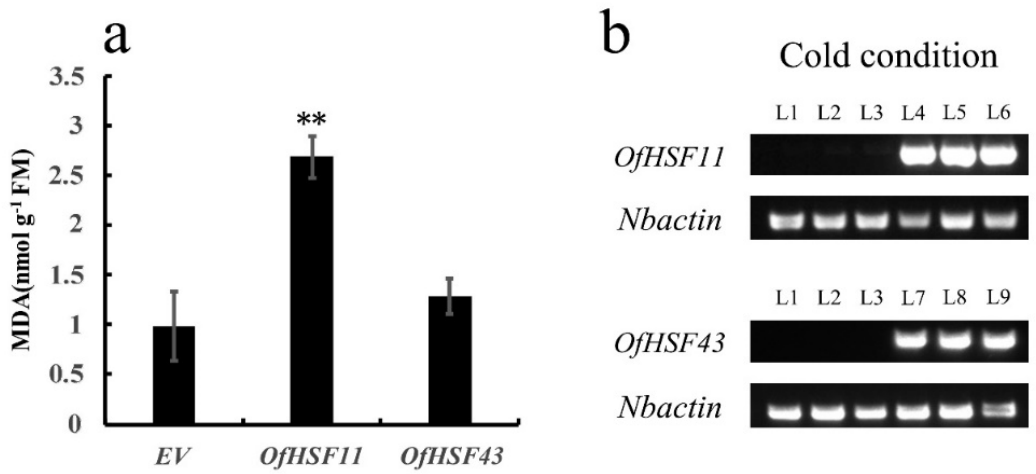

C
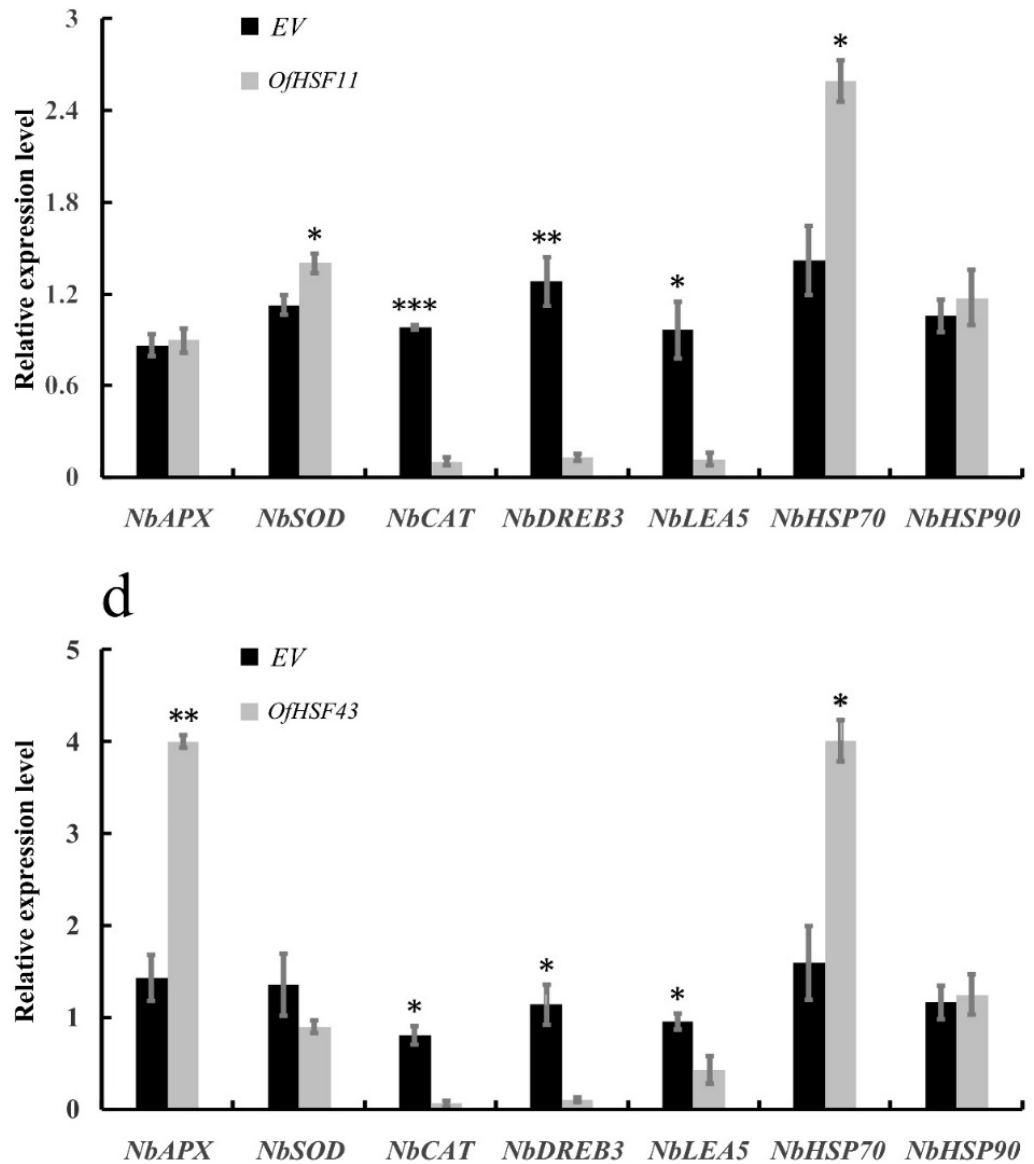

Figure 9. Physiological and biochemical changes in tobacco transiently transformed with OfHSF11 and OfHSF43, independently. (a) The MDA contents of transiently transformed tobacco after a 6-h cold treatment. (b) The sqRT-PCR analysis of OfHSF11 and OfHSF43 expression levels in transiently transformed tobacco. Three biological replicates were infiltrated independently with the empty vector (L1-3), 35S::GFP-OfHSF11 (L4-6) and 35S::GFP-OfHSF43 (L7-9). The qRT-PCR analysis of ROS-related and stress-response genes relative expression levels in 35S::GFP-OfHSF11 transformed tobacco (c), 35S::GFP-OfHSF43 transformed tobacco (d) and the controls after cold treatment. The internal reference gene was Nbactin. Values are means \pm SEs $(n=3)$. The asterisks indicate significant differences as assessed by independent sample $t$ test $\left({ }^{*} p<0.05,{ }^{* *} p<0.01,{ }^{* * *} p<0.001\right)$. 


\section{Discussion}

The members of the HSF gene family have been identified from many plant species; however, O. fragrans has 46 HSF genes, which is greater than those in many woody plants, such as $P$. trichocarpa (28) and $M$. domestica (25). There is also a large number of segmental duplications in the OfHSFs and a pair of tandem duplication events on the same chromosome (OfHSF41/42) (Figure S2). Whole-genome duplication (WGD) events may have occurred during the evolution of several plants, and they can result in gene family expansion [44]. Recent studies have shown that WGDs in M. domestica and P. bretschneideri may have resulted in the expansion of the HSF gene family [10]. Similarly, more than 14 million years ago, two WGD events occurred in O. fragrans [31]. The greater number of OfHSF members compared with other woody plant species might be the result of these WGD events.

In this study, 46 OfHSFs were identified from $O$. fragrans genome, and they were classified into three subfamilies according to their structures and phylogenetic relationships (Figure 1). Similar to their orthologs in A. thaliana, most of the OfHSFs (27) were classified in the A subfamily. Most OfHSFs were expressed higher in roots and leaves than in other tissues (such as stem and flower), indicating that these OfHSF members may play roles in abiotic stress (Figure 5a). The HR-A/B contains hydrophobic heptad repeats, which are characterized by a coiled-coil domain [6]. However, in O. fragrans, five OfHSFs were found to not contain the coiled-coil domain (Table S7). These OfHSFs generally had relatively low expression levels in different tissues and under cold-stress conditions compared with those OfHSFs that contained an oligomerization domain (Figure 5). The lack of an oligomerization domain in some HSFs has also been found in some other species, such as Camellia sinensis [45]. The absence of an oligomerization domain in some HSF member may significantly affect their abilities to bind to their target genes [7]. This, in turn, may affect their functions. In addition to these OfHSFs, the expression of OfHSF34 indicated that it might be involved in the development and senescence of floral organs. Similarly, DcHSFB2c is expressed highly in the late flowering stages of Dianthus caryophyllus [46]. OfHSFs of the A subfamily were expressed more consistently in different tissues than those of the B subfamily (Figure 5a). OfHSFs having tissue specificity may be associated with specific biological functions.

The expression of HSF family members can be induced by multiple abiotic stresses, and HSFs also play crucial roles in plant cold-stress tolerance [47,48]. For instance, DcHsfg and $\mathrm{DcHsf10}$ as A subfamily members are up-regulated rapidly after a $4{ }^{\circ} \mathrm{C}$ treatment, whereas DcHSf1 and DcHsf2, as B subfamily members, were down-regulated [49]. Similarly, the expression levels of OsHSFA3, $-4 d,-7$ and -9 are significantly increased under $4{ }^{\circ} \mathrm{C}$ lowtemperature conditions, whereas the expression levels of class $\mathrm{B}$ members decreased $[50,51]$. The OfHSFs were involved, to different degrees, in responding to cold stress (Figure $5 b$ ). In addition, similar expression trends were observed in cold-stress expression profiles of OfHSFs. Most members of class A were first up-regulated; however, in contrast, most OfHSFs of class B were down-regulated (Figure 5b). The expression patterns of five candidate cold-related OfHSFs also showed similar tendencies, and they were induced, to different degrees, under heat-stress conditions. OfHSF11 and OfHSF43 showed contrasting expression variation trends under cold-stress conditions, and notably, their expression levels in the recovery stage changed, approaching their pre-treatment levels (Figure 6a). Furthermore, these two OfHSFs were induced by heat stress (Figure 6c). This implied that OfHSF11 and OfHSF43 are involved in regulating plant responses to cold and heat stresses.

OfHSFs have many cis-acting elements that are involved in various hormonal and abiotic stress responses, especially elements related to ABA, MeJA, anaerobic induction and low temperature (Figure 3). Furthermore, we explored the expression patterns of OfHSF11 and OfHSF43 under many other treatment conditions. In response to waterlogging and drought stresses, the expression of OfHSF43 was continuously inhibited (Figure 7a). This may indicate that $\mathrm{OfHSF} 43$ is a negative regulator of responses to flooding and drought stress in O. fragrans. During a short-term salt-stress treatment in Fragaria vesca, FvHSFA2a 
and FvHSFC1 $a$ transcripts are induced and then decrease as the processing time increases. In contrast, the expression levels of FvHSFA3a, $-5 a,-9 a$ and FvHSFB $1 a$ increase in the middle or later periods of salt treatments [52]. An expression patterns analysis showed that OfHSF11 was induced by long-term salt stress, whereas OfHSF43 was rapidly up-regulated during a short-term salt treatment, indicating that these two transcription factors may be involved in the regulation of $O$. fragrans at different stages under salt-stress conditions.

The $\mathrm{ABA}, \mathrm{GA}_{3}$ and MeJA signals are important in plants [53-55]. The expression patterns of OfHSF11 in response to these hormonal treatments, as assessed by qRT-PCR, were similar, with the expression level decreasing at $6 \mathrm{~h}$ and then increasing (Figure $7 \mathrm{~b}$ ). The expression of OfHSF43 was inhibited during the $\mathrm{GA}_{3}$ treatment, but no significant change was observed during the MeJA treatment. OfHSF43 was downregulated at $6 \mathrm{~h}$ by the ABA treatment, and then, the expression returned its pre-treatment level. Similarly, in $C$. sinensis, CsHSFA2, $-B 2 a$ and $-B 2 c$ are down-regulated by exogenous ABA [45]. Moreover, OfHSF11 and OfHSF43 localized to the nucleus, which is a typical characteristic of transcription factors. These results indicate that these two OfHSFs play crucial roles in the plant regulatory processes under multiple abiotic and hormonal stresses.

MDA is closely related to cellular membrane damage under abiotic stress [56]. However, the member of HSF family that makes the decrease of plant cold tolerance by increasing MDA content has not been reported. The MDA content in A. thaliana overexpressing CsbZIP6 were higher than in wild-type plants after a freezing treatment, which led to the reduced cold tolerance of the plants [57]. Similarly, compared with the control plants, the tobacco transiently transformed with OfHSF11 had significantly higher leaf MDA contents (Figure 9a), indicating that the overexpression of OfHSF11 changed the membrane permeability of transiently transformed tobacco leaves and the cold tolerance of tobacco transiently transformed with OfHSF11 was significantly decreased. The MDA content in tobacco transiently transformed with OfHSF43 also increased, but not obviously $(p<0.01)$ (Figure 9a). Thus, OfHSF43 may be involved in the regulation of $O$. fragrans responses to cold stress through other pathways. Remarkably, the transcript levels of stress-related genes, such as $\mathrm{NbCAT}$ (ROS-related gene), NbDREB3 (cold-response regulatory gene) and $\mathrm{NbLEA5}$ (cold-stress defensive protein-encoding gene) were significant decreased in the OfHSF11-overexpression tobacco (Figure 9c). These results imply that the ROS-scavenging system might be disturbed in the OfHSF11-overexpression plants and this increased the plants sensitivity to cold-stress conditions (Figure S4).

\section{Conclusions}

The 46 HSF genes identified in O. fragrans were disproportionately localized on 17 chromosomes. The OfHSFs clustered into three classes on the basis of their phylogenetic relationships, and this was supported by the conserved motif distribution. The expansion of the OfHSF family was largely attributed to segmental duplication and WGD events. The expression pattern analysis of OfHSFs in different tissues revealed that some tissue-specific OfHSF expression might be involved in developmental regulatory processes. The RNA-seq data revealed that OfHSF genes can be induced to different degrees by cold stress. In particular, the expression levels of nuclear localized OfHSF11 and OfHSF43 during the recovery period shared a tendency to recover to the pre-cold treatment level. A significant increase in the MDA content in tobacco transiently transformed with OfHSF11 was shown, indicating that the overexpression of OfHSF11 reduced the tolerance of plants to cold stress. This result is also supported by the inhibited expression levels of three cold-response genes (NbCAT, NbDREB3 and NbLEA5). The promoter regions of OfHSF11 and OfHSF43 contain many stress-related elements, and the qRT-PCR results revealed that they were induced by multiple abiotic and hormonal stresses. This implied that OfHSF11 and OfHSF43 play important roles in plant responses to these stresses. This study provides new information regarding $O f H S F s$, and the results may facilitate an improvement in the cold-stress tolerance of O. fragrans. 
Supplementary Materials: The following supporting information can be downloaded at: https: / / www.mdpi.com/article/10.3390/horticulturae8010080/s1, Figure S1: Multiple sequence alignment of DNA-binding domains in OfHSFs, Figure S2: The collinearity analysis of 46 OfHSF genes, Figure S3: A repeat gel image for sqRT-PCR analysis of Nbactin expression levels in transiently transformed tobacco, Figure S4: A presumed model depicting the OfHSF11 in the regulation of cold stress tolerance, Table S1: Expression profiles of 46 OfHSF genes in seven different organs, Table S2: The expression levels of 46 OfHSF genes under cold stress, Table S3: The overview of stress treatments of O.fragrans, Table S4: List of primer sequences, Table S5: Summary information of 46 OfHSF genes, Table S6: The cis-acting element prediction of OfHSFs, Table S7: The predicted coiled-coil domain of OfHSFs.

Author Contributions: Conceptualization, J.B. and Y.Y.; methodology, J.B., M.Z. and Y.Y.; software, J.B.; validation, J.B., Z.Z., T.S. and H.D.; formal analysis, J.B.; data curation, J.B. and M.Z.; writingoriginal draft preparation, J.B.; writing-review and editing, X.Y., L.W. and Y.Y.; visualization, J.B.; funding acquisition, X.Y., L.W. and Y.Y. All authors have read and agreed to the published version of the manuscript.

Funding: This research was funded by the National Natural Science Foundation of China (Grant Nos. 32071828 and 31870695), the Natural Science Fund for Colleges and Universities in Jiangsu Province (20KJB220005), and the Priority Academic Program Development of Jiangsu Higher Education Institutions (PAPD).

Institutional Review Board Statement: Not applicable.

Informed Consent Statement: Not applicable.

Data Availability Statement: All data in this study could be found in the manuscript or supplemental materials.

Acknowledgments: We thank International Science Editing (http:/ / www.internationalscienceediting. com, accessed on 5 January 2022) for editing this manuscript.

Conflicts of Interest: The authors declare no conflict of interest.

\section{References}

1. Khan, S.A.; Li, M.Z.; Wang, S.M.; Yin, H.J. Revisiting the Role of Plant Transcription Factors in the Battle against Abiotic Stress. Int. J. Mol. Sci. 2018, 19, 1634. [CrossRef]

2. Guo, M.; Liu, J.H.; Ma, X.; Luo, D.X.; Gong, Z.H.; Lu, M.H. The Plant Heat Stress Transcription Factors (HSFs): Structure, Regulation, and Function in Response to Abiotic Stresses. Front. Plant Sci. 2016, 7, 114. [CrossRef] [PubMed]

3. Kotak, S.; Larkindale, J.; Lee, U.; von Koskull-Doring, P.; Vierling, E.; Scharf, K.D. Complexity of the heat stress response in plants. Curr. Opin. Plant Biol. 2007, 10, 310-316. [CrossRef]

4. Scharf, K.D.; Berberich, T.; Ebersberger, I.; Nover, L. The plant heat stress transcription factor (Hsf) family: Structure, function and evolution. Biochim. Biophys. Acta 2012, 1819, 104-119. [CrossRef]

5. Nover, L.; Bharti, K.; Döring, P.; Mishra, S.K.; Ganguli, A.; Scharf, K.D. Arabidopsis and the heat stress transcription factor world: How many heat stress transcription factors do we need? Cell Stress Chaperones 2001, 6, 177. [CrossRef]

6. Peteranderl, R.; Rabenstein, M.; Shin, Y.K.; Liu, C.W.; Wemmer, D.E.; King, D.S.; Nelson, H.C. Biochemical and biophysical characterization of the trimerization domain from the heat shock transcription factor. Biochemistry 1999, 38, 3559-3569. [CrossRef] [PubMed]

7. Boscheinen, O.; Lyck, R.; Queitsch, C.; Treuter, E.; Zimarino, V.; Scharf, K.D. Heat stress transcription factors from tomato can functionally replace HSF1 in the yeast Saccharomyces cerevisiae. Mol. Gen. Genet. 1997, 255, 322-331. [CrossRef]

8. Heerklotz, D.; Doring, P.; Bonzelius, F.; Winkelhaus, S.; Nover, L. The balance of nuclear import and export determines the intracellular distribution and function of tomato heat stress transcription factor HsfA2. Mol. Cell. Biol. 2001, 21, 1759-1768. [CrossRef] [PubMed]

9. Kotak, S.; Port, M.; Ganguli, A.; Bicker, F.; von Koskull-Doring, P. Characterization of C-terminal domains of Arabidopsis heat stress transcription factors (Hsfs) and identification of a new signature combination of plant class A Hsfs with AHA and NES motifs essential for activator function and intracellular localization. Plant J. 2004, 39, 98-112. [CrossRef]

10. Qiao, X.; Li, M.; Li, L.; Yin, H.; Wu, J.; Zhang, S. Genome-wide identification and comparative analysis of the heat shock transcription factor family in Chinese white pear (Pyrus bretschneideri) and five other Rosaceae species. BMC Plant Biol. 2015, 15, 12. [CrossRef]

11. Giorno, F.; Guerriero, G.; Baric, S.; Mariani, C. Heat shock transcriptional factors in Malus domestica: Identification, classification and expression analysis. BMC Genom. 2012, 13, 639. [CrossRef] [PubMed]

12. Zhu, Y.X.; Yan, H.W.; Wang, Y.Y.; Feng, L.; Chen, Z.; Xiang, Y. Genome Duplication and Evolution of Heat Shock Transcription Factor (HSF) Gene Family in Four Model Angiosperms. J. Plant Growth Regul. 2016, 35, 903-920. [CrossRef] 
13. Jin, G.H.; Gho, H.J.; Jung, K.H. A systematic view of rice heat shock transcription factor family using phylogenomic analysis J. Plant Physiol. 2013, 170, 321-329. [CrossRef] [PubMed]

14. Miller, G.; Mittler, R. Could heat shock transcription factors function as hydrogen peroxide sensors in plants? Ann. Bot. 2006, 98, 279-288. [CrossRef] [PubMed]

15. Zhang, S.X.; Xu, Z.S.; Li, P.S.; Yang, L.; Wei, Y.Q.; Chen, M.; Li, L.C.; Zhang, G.S.; Ma, Y.Z. Overexpression of TaHSF3 in Transgenic Arabidopsis Enhances Tolerance to Extreme Temperatures. Plant Mol. Biol. Rep. 2013, 31, 688-697. [CrossRef]

16. Chinnusamy, V.; Zhu, J.; Zhu, J.K. Cold stress regulation of gene expression in plants. Trends Plant Sci. 2007, 12, 444-451. [CrossRef] [PubMed]

17. Gill, S.S.; Tuteja, N. Reactive oxygen species and antioxidant machinery in abiotic stress tolerance in crop plants. Plant Physiol. Biochem. 2010, 48, 909-930. [CrossRef]

18. John, R.; Anjum, N.A.; Sopory, S.K.; Akram, N.A.; Ashraf, M. Some key physiological and molecular processes of cold acclimation. Biol. Plantarum. 2016, 60, 603-618. [CrossRef]

19. Xu, Y.; Hu, W.; Liu, J.; Song, S.; Hou, X.; Jia, C.; Li, J.; Miao, H.; Wang, Z.; Tie, W.; et al. An aquaporin gene MaPIP2-7 is involved in tolerance to drought, cold and salt stresses in transgenic banana (Musa acuminata L.). Plant Physiol. Biochem. 2020, $147,66-76$. [CrossRef]

20. Dong, C.; Zhang, Z.; Qin, Y.; Ren, J.P.; Huang, J.F.; Wang, B.L.; Lu, H.L.; Cai, B.H.; Tao, J.M. VaCBF1 from Vitis amurensis associated with cold acclimation and cold tolerance. Acta Physiol. Plant 2013, 35, 2975-2984. [CrossRef]

21. Swindell, W.R.; Huebner, M.; Weber, A.P. Transcriptional profiling of Arabidopsis heat shock proteins and transcription factors reveals extensive overlap between heat and non-heat stress response pathways. BMC Genom. 2007, 8, 125. [CrossRef] [PubMed]

22. Yokotani, N.; Ichikawa, T.; Kondou, Y.; Matsui, M.; Hirochika, H.; Iwabuchi, M.; Oda, K. Expression of rice heat stress transcription factor OsHsfA2e enhances tolerance to environmental stresses in transgenic Arabidopsis. Planta 2008, 227, 957-967. [CrossRef] [PubMed]

23. Huang, Y.C.; Niu, C.Y.; Yang, C.R.; Jinn, T.L. The Heat Stress Factor HSFA6b Connects ABA Signaling and ABA-Mediated Heat Responses. Plant Physiol. 2016, 172, 1182-1199. [CrossRef]

24. Bechtold, U.; Albihlal, W.S.; Lawson, T.; Fryer, M.J.; Sparrow, P.A.; Richard, F.; Persad, R.; Bowden, L.; Hickman, R.; Martin, C.; et al. Arabidopsis HEAT SHOCK TRANSCRIPTION FACTORA1b overexpression enhances water productivity, resistance to drought, and infection. J. Exp. Bot. 2013, 64, 3467-3481. [CrossRef] [PubMed]

25. Chen, X.; Yang, X.; Xie, J.; Ding, W.; Li, Y.; Yue, Y.; Wang, L. Biochemical and Comparative Transcriptome Analyses Reveal Key Genes Involved in Major Metabolic Regulation Related to Colored Leaf Formation in Osmanthus fragrans 'Yinbi Shuanghui' during Development. Biomolecules 2020, 10, 549. [CrossRef]

26. Cai, X.; Mai, R.Z.; Zou, J.J.; Zhang, H.Y.; Zeng, X.L.; Zheng, R.R.; Wang, C.Y. Analysis of aroma-active compounds in three sweet osmanthus (Osmanthus fragrans) cultivars by GC-olfactometry and GC-MS. J. Zhejiang Univ. Sci. B 2014, 15, 638-648. [CrossRef] [PubMed]

27. Yang, J.; Wang, S.; Xia, H.X.; Guo, P.; Wang, Y.H.; Shang, F.D.; Li, Y. Comparative analysis of candidate genes for multi-season flowering in two varieties of sweet osmanthus. Sci. Hortic. 2021, 285, 110175. [CrossRef]

28. Zou, J.J.; Zhou, Y.; Cai, X.; Wang, C.Y. Increase in DNA fragmentation and the role of ethylene and reactive oxygen species in petal senescence of Osmanthus fragrans. Postharvest. Biol. Technol. 2014, 93, 97-105. [CrossRef]

29. Geng, X.M.; Zhang, Y.M.; Wang, L.G.; Yang, X.L. Pretreatment with High-Dose Gamma Irradiation on Seeds Enhances the Tolerance of Sweet Osmanthus Seedlings to Salinity Stress. Forests 2019, 10, 406. [CrossRef]

30. Li, Y.L.; Li, L.; Ding, W.J.; Li, H.Y.; Shi, T.T.; Yang, X.L.; Wang, L.G.; Yue, Y.Z. Genome-wide identification of Osmanthus fragrans bHLH transcription factors and their expression analysis in response to abiotic stress. Environ. Exp. Bot. 2020, 172, 103990. [CrossRef]

31. Yang, X.; Yue, Y.; Li, H.; Ding, W.; Chen, G.; Shi, T.; Chen, J.; Park, M.S.; Chen, F.; Wang, L. The chromosome-level quality genome provides insights into the evolution of the biosynthesis genes for aroma compounds of Osmanthus fragrans. Hortic. Res. 2018, 5, 72. [CrossRef]

32. Chen, C.; Chen, H.; Zhang, Y.; Thomas, H.R.; Frank, M.H.; He, Y.; Xia, R. TBtools: An Integrative Toolkit Developed for Interactive Analyses of Big Biological Data. Mol. Plant 2020,13, 1194-1202. [CrossRef]

33. Tamura, K.; Stecher, G.; Kumar, S. MEGA11: Molecular Evolutionary Genetics Analysis Version 11. Mol. Biol. Evol. 2021, 38, 3022-3027. [CrossRef]

34. Bailey, T.L.; Johnson, J.; Grant, C.E.; Noble, W.S. The MEME Suite. Nucleic Acids Res. 2015, 43, W39-W49. [CrossRef]

35. Wang, Y.; Tang, H.; Debarry, J.D.; Tan, X.; Li, J.; Wang, X.; Lee, T.H.; Jin, H.; Marler, B.; Guo, H.; et al. MCScanX: A toolkit for detection and evolutionary analysis of gene synteny and collinearity. Nucleic Acids Res. 2012, 40, e49. [CrossRef] [PubMed]

36. Lescot, M.; Dehais, P.; Thijs, G.; Marchal, K.; Moreau, Y.; Van de Peer, Y.; Rouze, P.; Rombauts, S. PlantCARE, a database of plant cis-acting regulatory elements and a portal to tools for in silico analysis of promoter sequences. Nucleic Acids Res. 2002, 30, 325-327. [CrossRef]

37. Yue, Y.Z.; Li, L.; Li, Y.L.; Li, H.Y.; Ding, W.J.; Shi, T.T.; Chen, G.W.; Yang, X.L.; Wang, L.G. Genome-Wide Analysis of NAC Transcription Factors and Characterization of the Cold Stress Response in Sweet Osmanthus. Plant Mol. Biol. Rep. 2020, 38 , 314-330. [CrossRef] 
38. Singh, V.K.; Mangalam, A.K.; Dwivedi, S.; Naik, S. Primer premier: Program for design of degenerate primers from a protein sequence. Biotechniques 1998, 24, 318-319. [CrossRef] [PubMed]

39. Yue, Y.; Liu, J.; Shi, T.; Chen, M.; Li, Y.; Du, J.; Jiang, H.; Yang, X.; Hu, H.; Wang, L. Integrating Transcriptomic and GC-MS Metabolomic Analysis to Characterize Color and Aroma Formation during Tepal Development in Lycoris longituba. Plants 2019, 8, 53. [CrossRef]

40. Zhang, C.; Fu, J.; Wang, Y.; Bao, Z.; Zhao, H. Identification of Suitable Reference Genes for Gene Expression Normalization in the Quantitative Real-Time PCR Analysis of Sweet Osmanthus (Osmanthus fragrans Lour.). PLoS ONE 2015, 10, e0136355. [CrossRef]

41. Livak, K.J.; Schmittgen, T.D. Analysis of relative gene expression data using real-time quantitative PCR and the 2(-Delta Delta C(T)) Method. Methods 2001, 25, 402-408. [CrossRef]

42. Jin, C.; Huang, X.S.; Li, K.Q.; Yin, H.; Li, L.T.; Yao, Z.H.; Zhang, S.L. Overexpression of a bHLH1 Transcription Factor of Pyrus ussuriensis Confers Enhanced Cold Tolerance and Increases Expression of Stress-Responsive Genes. Front. Plant Sci. 2016, 7, 441. [CrossRef] [PubMed]

43. Zhao, Q.; Xiang, X.; Liu, D.; Yang, A.; Wang, Y. Tobacco Transcription Factor NtbHLH123 Confers Tolerance to Cold Stress by Regulating the NtCBF Pathway and Reactive Oxygen Species Homeostasis. Front. Plant Sci. 2018, 9, 381. [CrossRef] [PubMed]

44. Cui, L.; Wall, P.K.; Leebens-Mack, J.H.; Lindsay, B.G.; Soltis, D.E.; Doyle, J.J.; Soltis, P.S.; Carlson, J.E.; Arumuganathan, K.; Barakat, A.; et al. Widespread genome duplications throughout the history of flowering plants. Genome Res. 2006, 16, 738-749. [CrossRef] [PubMed]

45. Zhang, X.; Xu, W.; Ni, D.; Wang, M.; Guo, G. Genome-wide characterization of tea plant (Camellia sinensis) Hsf transcription factor family and role of CsHsfA2 in heat tolerance. BMC Plant Biol 2020, 20, 244. [CrossRef] [PubMed]

46. Li, W.; Wan, X.L.; Yu, J.Y.; Wang, K.L.; Zhang, J. Genome-Wide Identification, Classification, and Expression Analysis of the Hsf Gene Family in Carnation (Dianthus caryophyllus). Int. J. Mol. Sci. 2019, 20, 5233. [CrossRef]

47. Ogawa, D.; Yamaguchi, K.; Nishiuchi, T. High-level overexpression of the Arabidopsis HsfA2 gene confers not only increased themotolerance but also salt/osmotic stress tolerance and enhanced callus growth. J. Exp. Bot. 2007, 58, 3373-3383. [CrossRef]

48. Pirkkala, L.; Nykanen, P.; Sistonen, L. Roles of the heat shock transcription factors in regulation of the heat shock response and beyond. FASEB J. 2001, 15, 1118-1131. [CrossRef] [PubMed]

49. Huang, Y.; Li, M.Y.; Wang, F.; Xu, Z.S.; Huang, W.; Wang, G.L.; Ma, J.; Xiong, A.S. Heat shock factors in carrot: Genome-wide identification, classification, and expression profiles response to abiotic stress. Mol. Biol. Rep. 2015, 42, 893-905. [CrossRef]

50. Liu, A.L.; Zou, J.; Zhang, X.W.; Zhou, X.Y.; Wang, W.F.; Xiong, X.Y.; Chen, L.Y.; Chen, X.B. Expression Profiles of Class A Rice Heat Shock Transcription Factor Genes Under Abiotic Stresses. J. Plant Biol. 2010, 53, 142-149. [CrossRef]

51. Mittal, D.; Chakrabarti, S.; Sarkar, A.; Singh, A.; Grover, A. Heat shock factor gene family in rice: Genomic organization and transcript expression profiling in response to high temperature, low temperature and oxidative stresses. Plant Physiol. Biochem. 2009, 47, 785-795. [CrossRef] [PubMed]

52. Hu, Y.; Han, Y.T.; Wei, W.; Li, Y.J.; Zhang, K.; Gao, Y.R.; Zhao, F.L.; Feng, J.Y. Identification, isolation, and expression analysis of heat shock transcription factors in the diploid woodland strawberry Fragaria vesca. Front. Plant Sci. 2015, 6, 736. [CrossRef] [PubMed]

53. Qi, X.N.; Xiao, Y.Y.; Fan, Z.Q.; Chen, J.Y.; Lu, W.J.; Kuang, J.F. A banana fruit transcriptional repressor MaERF10 interacts with MaJAZ3 to strengthen the repression of JA biosynthetic genes involved in MeJA-mediated cold tolerance. Postharvest Biol. Technol. 2016, 120, 222-231. [CrossRef]

54. Hu, Z.; Weijian, L.; Yali, F.; Huiquan, L. Gibberellic acid enhances postharvest toon sprout tolerance to chilling stress by increasing the antioxidant capacity during the short-term cold storage. Sci. Hortic. 2018, 237, 184-191. [CrossRef]

55. Gusta, L.V.; Trischuk, R.; Weiser, C.J. Plant cold acclimation: The role of abscisic acid. J. Plant Growth Regul. 2005, 24, 308-318. [CrossRef]

56. Mellacheruvu, S.; Tamirisa, S.; Vudem, D.R.; Khareedu, V.R. Pigeonpea Hybrid-Proline-Rich Protein (CcHyPRP) Confers Biotic and Abiotic Stress Tolerance in Transgenic Rice. Front. Plant Sci. 2015, 6, 1167. [CrossRef]

57. Wang, L.; Cao, H.; Qian, W.; Yao, L.; Hao, X.; Li, N.; Yang, Y.; Wang, X. Identification of a novel bZIP transcription factor in Camellia sinensis as a negative regulator of freezing tolerance in transgenic arabidopsis. Ann. Bot. 2017, 119, 1195-1209. [CrossRef] [PubMed] 